\title{
A Comprehensive Comparison of Air Pollution in Main Cities in Sri Lanka
}

\author{
Attanayake D.N.S. ${ }^{*}$ and Abeygunawardana R.A.B. \\ Department of Statistics, Faculty of Science, University of Colombo, Colombo 03, Sri Lanka \\ sandarekha89@yahoo.com
}

\begin{abstract}
Industrialization, increasing population and the vast usage of vehicles have been deteriorated the quality of air in developing countries. Sri Lanka is one such developing country facing the problem in quality of the air severely. Since Colombo is the commercial capital of Sri Lanka it is a foremost victim of environmental pollution and many researches have been conducted to control the air pollution in Colombo. However when concerning the quality of air, attention should be paid on the other cities as well, which are more populated and industrialized, since air pollution is a silent hazard that may even cause death to human beings. Main objectives of this research are to analyse the air quality data and to compare and contrast the pollutant levels, at the four different locations Colombo, Kandy, Maharagama and Kurunegala. Data were collected by a leading environment organization, Cleanco Lanka Limited and published in "Ada" news paper. Concentrations measured in $\mathrm{mg} / \mathrm{m}^{3}$ for the five criterion air pollutants; Carbon Monoxide (CO), Sulfur Dioxide $\left(\mathrm{SO}_{2}\right)$, Nitrogen Dioxide $\left(\mathrm{NO}_{2}\right)$, Ozone $\left(\mathrm{O}_{3}\right)$ and Particulate Matter (PM 10) were gathered during the time period 1.00 p.m. to 4.00 p.m. The period October 2010 to April 2013 was considered for this study. Data are analysed using descriptive statistical techniques including summary measurements, graphical representations and correlation analysis. Furthermore, univariate statistical control charts are drawn to assess the quality of air of the selected cities. The data reveals that the concentrations of $\mathrm{CO}$ and $\mathrm{NO}_{2}$ are high at Colombo and the concentrations of the five pollutants are comparatively large at Maharagama on average, indicating that the other cities may also highly polluted as the commercial capital of Sri Lanka. However, the concentrations of the air pollutants are decreasing after February, 2011 whilst the PM 10 concentration shows erratic movements around the maximum permissible level of $0.5 \mathrm{mg} / \mathrm{m}^{3}$. It should be affirmed that the $\mathrm{CO}$ concentration has not exceeded the maximum permissible level during the past two years. Moreover, the relationships between primary and secondary air pollutants such as $\mathrm{O}_{3}$ with $\mathrm{CO}$ and $\mathrm{NO}_{2}$ can be examined through the correlation structure of the data.
\end{abstract}

Keywords: Air pollution, Air pollutants, Ambient air quality index 